\title{
Legitimación procesal de las asociaciones de consumidores
}

\author{
Franco Raschetti \\ Pontificia Universidad Católica Argentina, Rosario, Argentina \\ $\bigotimes$ francoraschetti@uca.edu.ar \\ 望㬐 Fecha de recepción: 17/03/2021 - Fecha de aceptación: 26/05/2021
}

\begin{abstract}
Cómo citar este artículo: Raschetti, F. (2022). Legitimación procesal de las asociaciones de consumidores. Revista Perspectivas de las Ciencias Económicas y Jurídicas. Vol. 12, $\mathrm{N}^{\circ} 1$ (enero-junio). Santa Rosa: FCEyJ (UNLPam); EdUNLPam; pp. 61-80. ISSN 2250-4087, e-ISSN 2445-8566. http://dx.doi.org/10.19137/ perspectivas-2022-v12n1a05
\end{abstract}

Resumen: El presente trabajo versa sobre la legitimación procesal de las asociaciones de consumidores como parte actora en un reclamo judicial. A tales efectos desbrozaremos primeramente el concepto y contenido de la "legitimación procesal” para, luego, valorar críticamente la actualidad de las categorías tradicionales relativas a la relación jurídica protegida de la cual parte la legitimación procesal (derecho subjetivo, interés legítimo, interés simple, derechos de incidencia colectiva). Dilucidado ello, volcaremos el análisis en la conceptualización de los derechos de incidencia colectiva y bajo qué condiciones y requisitos las asociaciones de consumidores pueden impetrar reclamos judiciales en pos de la tutela de tales derechos en el ámbito de los derechos de consumidores y usuarios.

Palabras clave: consumidores; asociaciones; legitimación procesal; reclamo judicial.

\section{Procedural legitimacy of consumer associations}

Abstract: This work deals with the procedural legitimacy of consumer associations as plaintiffs in a legal claim. To this end, we will first unravel the concept and content of "procedural legitimacy" to then critically assess the current status of the traditional categories related to the protected 
legal relationship from which the procedural legitimacy starts (subjective right, legitimate interest, simple interest, rights of collective incidence). Once this has been elucidated, we will turn the analysis into the conceptualization of collective advocacy rights and under what conditions and requirements consumer associations can file legal claims in pursuit of the protection of such rights in the field of consumer and user rights.

Key words: consumers; associations; procedural legitimacy; judicial claim.

\section{Legitimidade processual de associações de consumidores}

Resumo: Este trabalho trata da legitimidade processual de associações de consumidores como autoras em uma ação judicial. Para tanto, primeiro desvendaremos o conceito e o conteúdo de "legitimidade processual" para, em seguida, avaliar criticamente o estado atual das categorias tradicionais relacionadas à relação jurídica protegida a partir da qual se inicia a legitimidade processual (direito subjetivo, interesse legítimo, interesse simples, direitos de incidência coletiva). Uma vez que isso tenha sido elucidado, faremos a análise na conceituação dos direitos de advocacy coletivo e em que condições e requisitos as associações de consumidores podem mover ações judiciais em busca da proteção de tais direitos no campo dos direitos do consumidor e do usuário.

Palavras-chave: consumidores; associações; legitimidade processual; reclamação judicial.

\section{Introducción}

En el presente opúsculo trataremos un aspecto que, consideramos, es de vital importancia para la protección y tutela de los derechos de los consumidores como es la legitimación procesal de las asociaciones de consumidores en tanto protagonistas centrales para vehiculizar sus reclamos judiciales, aunando en una postura y proceso único las pretensiones de un colectivo de actores, los cuales no deberán iniciar individualmente sus pedimentos aventándose así los costos, dificultades y extensión temporal que ello importa. Mal podría discutirse la simplificación procesal que esto trasunta y cómo, en definitiva, la actuación de las asociaciones de consumidores contribuye al logro de la efectividad de la tutela a los derechos de los consumidores, ${ }^{(1)}$ exigencia de eficacia que encuentra expresa recepción en nuestra Carta Magna, ${ }^{(2)}$ la cual reza: "La legislación establecerá procedimientos eficaces para la prevención y solución de conflictos, y los marcos regulatorios de los servicios públicos de competencia nacional, pre-

(1) En tren de dicha eficacia, la Ley 24.240 de Defensa del Consumidor (1993) establece que incumbe al Estado nacional, a la Ciudad Autónoma de Buenos Aires, a las provincias y a los municipios fomentar la creación y el funcionamiento de las asociaciones de consumidores y usuarios y la participación de la comunidad en ellas (art. 60) y que el Estado nacional podrá disponer el otorgamiento de contribuciones financieras con cargo al presupuesto nacional a las asociaciones de consumidores para cumplimentar con los objetivos mencionados en la norma (art. 62).

(2) Norma que, sabido es, consagra los llamados derechos fundamentales de los consumidores en el marco de, justamente, la relación de consumo (Stiglitz, 2015, p. 309). Jurisprudencialmente, se ha destacado que se trata de uno de los organismos que expresamente reconoce la Constitución Nacional para llevar adelante este tipo de procesos de carácter colectivo (JFed. $1^{19}$ Instancia Dolores, 2018). 
viendo la necesaria participación de las asociaciones de consumidores y usuarios y de las provincias interesadas, en los organismos de control" (art. 42 CN).

No obstante la importancia y vastedad de la temática reseñada, múltiples aspectos de la misma continúan en entredicho y, a los efectos del estudio que nos convoca, comenzaremos por brindar una breve conceptualización de lo que, a nuestro criterio, corresponde entender por el concepto de legitimación -cuestión esta que ha merecido debates en la doctrina especializada-; luego, viraremos el análisis a las categorías que se han esbozado tradicionalmente para describir el contenido de la conocida "relación jurídica tutelada" que autoriza y dota de contenido a la legitimación y así verificar la actualidad, en su caso, de las mentadas categorías. Finalmente, nos detendremos en una de ellas -los derechos de incidencia colectiva- para profundizar su definición y enlazar con dicha temática la posibilidad de acción de las asociaciones de consumidores para definir, en definitiva, los presupuestos necesarios para su actuación en resguardo de los derechos de los consumidores.

\section{El problema de la legitimación: un concepto de perfiles controvertidos}

La doctrina procesalista es conteste en comprender que la voz "legitimación" es un concepto de múltiples significaciones posibles sobre el cual, desde un punto de vista estrictamente jurídico, no existen consensos suficientes para verificar una postura clara y unívoca al respecto. Se impone primeramente distinguir a la capacidad procesal de la legitimación procesal. Al respecto seguimos a Palacio (1970, p. 32) para quien mientras la primera habilita a actuar en un número indeterminado de procesos, con prescindencia de las concretas relaciones o estados jurídicos que en ellos se controvierten, la segunda se refiere a la idoneidad especialmente atribuida para pretender o contradecir con respecto a la específica materia sobre la que versa el proceso.

Surge de modo claro la distinción ontológica entre ambos institutos, dado que cada uno de ellos se ocupa de un ámbito diverso e independiente de la posible actuación procesal de un sujeto: la capacidad atañe a la aptitud legal "en abstracto" de una persona para ser parte en un proceso y titularizar los derechos, deberes, obligaciones y cargas que surjan como consecuencia del proceso (Alvarado Velloso, 2005, p. 89);(3) por el contrario, la legitimación apunta a un análisis en concreto sobre la suficiente vinculación entre quien pretende ser parte (con capacidad o no) y la pretensión que se erige como objeto del procedimiento en cuestión. Se concluye así que se puede ser capaz para estar en juicio y no estar legitimado y, a su vez, se puede estar legitimado y no ser capaz para estar en juicio (Trionfetti, 2010, pp. 474-475).

(3) El autor rosarino enfoca la capacidad procesal desde tres puntos de vista: la capacidad jurídica para ser parte procesal, la capacidad procesal para actuar personalmente y por sí mismo en un proceso y, finalmente, la capacidad procesal para postular por sí mismo en un proceso. 
La noción de capacidad y la de legitimación cobran vigencia en segmentos diferentes del derecho de postulación de todo ciudadano, pero ambas deben reunirse de modo inexcusable a la hora de ejercer este derecho. Conforme Arazi (2004, p. 117), la persona que pide la sentencia judicial y aquella respecto de la cual se pide se encuentran, con relación al hecho invocado, en una situación individual que las hace aparecer como especialmente calificadas para afirmar y contradecir respecto a la materia en cuestión. A este vínculo concreto debe serle añadido inexcusablemente la capacidad jurídica y procesal de cada una de las partes contendientes a los fines de poder postular sus derechos de modo legítimo y suficiente. En caso de fracasar la vigencia de alguno de estos elementos, en modo alguno podría defenderse la constitución acabada de la relación jurídica procesal habida cuenta de la falla existente en los presupuestos ineludibles que la misma reclama para sí.

Luego, creemos que la legitimación se vincula necesariamente con la pretensión y no con el derecho de acción. Este último, asociado según Guasp (1996, p. 593) al poder reconocido por el Estado de acudir a los tribunales de justicia para formular pretensiones, parece erigirse por fuera de aquello que el actor le reclama al demandado y que se define como objeto del proceso. En otros términos, el derecho de peticionar ante el Estado es extraño al análisis particular y específico que reclama la legitimación. Distinta es la relación de esta con la pretensión, ya que la legitimación, vale decir esa ligazón del caso concreto sobre aquello que se pretende, se posiciona como el fundamento, la razón de la pretensión; como decía Carnelutti (1959), "el arma con que la pretensión opera en el campo del derecho, es la razón" (p. 32).(4) Esta relación con la pretensión la ha manifestado el Máximo Tribunal nacional al determinar que la carencia de legitimación procesal se configura cuando una de las partes no es titular de la relación jurídica sustancial en que se sustenta la pretensión, con prescindencia de que esta tenga o no fundamento (CSJN, Fallos 312:2138).

Así como la pretensión representa el objeto del proceso, es decir, las razones por las que el actor se presenta ante la jurisdicción y plantea en su demanda un determinado conflicto de intereses (cfr. Gozaíni, 1999, p. 43), no podemos afirmar que la misma se encuentre plenamente configurada si no se sustenta en una legitimación suficiente del pretensor. Es por ello que, desde el punto de vista procesal o formal, la legitimación es de una importancia mayúscula para el acceso a la jurisdicción, así como también para el sostenimiento cabal de la pretensión en él deducida.

En definitiva, nos inclinamos aquí por la mentada legitimación ad causam, la cual ha sido hábilmente definida como un tipo de relación entre relaciones que se verifica por comparación. Para esta postura, a la cual adscribimos, el procedimiento comparativo consiste en establecer y verificar que quien está ubicado 
en el proceso como parte o intenta ser tenido por tal en un proceso determinado, está autorizado jurídicamente para pretender o ser pretendido, es decir, para solicitar y ser alcanzado con el efecto jurídico perseguido con el desarrollo del proceso y la sentencia, con fundamento en el derecho de fondo (Trionfetti, 2010, p. 472), para lo cual es menester que dicha situación se mantenga durante la tramitación total del proceso y subsistir al momento de la decisión que corresponda adoptar. ${ }^{(5)}$

Deseamos destacar que seguimos, a su vez, a Marienhoff (1986, p. 899) cuando apunta la ambivalencia del concepto de legitimación, el cual, lejos de ceñirse de manera pura y exclusiva a un problema formal o procesal, también es un problema del derecho material o sustancial. Ciertamente, la noción de legitimación no se agota, aunque la comprende, en la determinada relación de las partes-personas con la pretensión deducida en el proceso, sino que esa idoneidad específica se deriva o vincula con el problema de fondo a discutir en el pleito.

\section{Actualidad de las categorías tradicionales de clasificación de las situaciones jurídicas tuteladas}

Tradicionalmente, para avizorar la presencia de una relación jurídica tutelada y, en consecuencia, la legitimación suficiente para reclamar en base a la misma, se ha distinguido desde la doctrina cuatro grandes grupos, a saber: derecho subjetivo, interés legítimo, interés simple y derechos de incidencia colectiva. De este modo, dependiendo de la categoría en la cual se ubique el supuesto de hecho, se colige la factibilidad o procedencia de la pretensión esgrimida judicialmente: el derecho subjetivo siempre habilitaba la reclamación, el interés legítimo solo en determinadas ocasiones, el interés simple ${ }^{(6)}$ no es suficiente más que para una mera denuncia(7) 0 , en su caso, para incoar una acción popular (no receptada en nuestro derecho positivo), ${ }^{(8)}$ y los derechos de incidencia

(5) Recordado es el precepto de nuestra Corte de que "... [l]as sentencias de la Corte deben atender a las circunstancias existentes al momento de la decisión. Ver: CSJN (Fallos: 310:670; Fallos 312:555; Fallos 320:2603).

(6) La Corte Suprema de Justicia de la Nación, en el considerando noveno del fallo "Halabi" (2009), determinó en modo contundente y en relación a los intereses simples que no se admite una acción que persiga el control de la mera legalidad de una disposición. Reafirma de este modo el Máximo Tribunal la doctrina asentada en los pronunciamientos: "Polino, Héctor y otro..." (1994) y "Rodríguez, Jorge..." (1997).

(7) Tradicionalmente, esta categoría de intereses ha sido despojada de protección judicial efectiva con el argumento de que no tiene un derecho personal y directo que defender, en razón de que manifiestan un simple perjuicio que, prima facie, no está legalmente protegido. Ver, al respecto, Gozaíni (2012, pp. 119 y ss.).

(8) Es entendimiento mayoritario que en materia de amparo no es correcto defender la posibilidad de configuración de una acción popular, así, en CSJN, "Mujeres por la Vida..." (2006), se arguyó en el voto de la Dra. Argibay que el art. 43 no ha instaurado una acción popular. No obstante ello encontramos un supuesto en el cual se tutela al interés simple como relación jurídica protegida. Hablamos del art. $5^{\circ}$ de la ley 23.098 que regula la posibilidad de promoción de la acción de hábeas corpus por cualquier persona en los siguientes términos: "La denuncia de hábeas corpus podrá ser interpuesta por la persona que afirme encontrarse en las condiciones previstas por los artículos 3 y 4o por cualquier otra en su favor". 
colectiva permitían la acción, pero cuando se satisfacen determinados requisitos, que luego veremos.

En los últimos tiempos, y fundamentalmente luego de la reforma constitucional de 1994, se ha fortalecido la doctrina que busca dejar atrás el distingo arriba apuntado proponiendo la superación de aquella segmentación en compartimientos estancos de tutela jurídica cuya virtualidad no hacía más que contener y filtrar inadecuadamente, en muchos casos, el acceso a la jurisdicción. En el derecho nacional, una importante doctrina evidencia una modificación del derecho subjetivo, el cual, forjado sobre la temática del derecho privado, es instrumento no apto ante las nuevas manifestaciones de la convivencia y ante los intereses colectivos plasmados en la Carta Magna (Morello y Stiglitz, 1989, p. 117). Otros autores (Gordillo, 2003, p. IV-I; Barra, 1980, p. 274) enseñan que no existen diferencias sustanciales que autoricen a mantener la independencia del interés legítimo.

La incorporación de los nuevos derechos y garantías en los arts. 41 y siguientes de nuestra Carta Magna, y su estrecha vinculación con los derechos de incidencia colectiva, obliga a la doctrina a reformular las modalidades de acceso a la jurisdicción, ya que los límites entre las categorías de situaciones jurídicas se desdibujan y aparecen como poco claros. De esta manera, si bien continuaremos refiriéndonos a aquellas, no debe perderse de vista que la nueva realidad social impone una mirada amplia, flexible y sin dogmatismos en lo que respecta a la conformación de la categoría correspondiente a los fines de garantizar la efectiva tutela judicial a través de un acceso a la justicia de ribetes amplios. No se desconocen ni olvidan los derechos individuales, sino que ellos se adaptan a aquellas situaciones en las que una variedad de sujetos se ve afectado por una idéntica situación.

Incluso en materia de la categoría de "interés legítimo", García Pullés (2004, p. 562) relata que los italianos dividieron el control contencioso administrativo entre tribunales administrativos y judiciales según se afectaran derechos subjetivos o intereses legítimos, extremo que fortaleció la importancia de un concepto que se exportó o, mejor dicho, que nosotros importamos con la proverbial amplitud de un país de raigambre inmigratoria. Pues bien, como hubiera destacado Fiorini (1997, p. 60), la clasificación perdía importancia en aquellos países donde los distintos recursos contenciosos administrativos se desenvuelven concurrentemente ante un mismo órgano, con lo cual tal distinción no debería ser de contundente y extendido recibo en nuestro derecho, pero lo cierto es que la doctrina ha continuado realizando esfuerzos ingentes para establecer una escisión clara entre ambos conceptos con consecuencias prácticas de relevancia en cada uno de ellos, lo que implica un desfasaje "histórico" y "jurídico" en la idea de mantener tal escisión.

Para concluir, lo aquí apuntado no intenta borrar los criterios clasificatorios. De hecho, en los códigos procesales locales y en los trabajos doctrinarios los 
mismos persisten y siguen gozando de vigencia práctica, pero sucede que en muchos supuestos, y en pos de la tutela judicial efectiva y el acceso a la jurisdicción, deben flexibilizarse los requisitos de procedencia de cada uno de ellos en aras de evitar toda denegación de justicia y la correspondiente frustración de derechos e intereses que la misma trae aparejada por el solo hecho de subsumir dogmáticamente una situación de hecho en una de las categorías apuntadas. Reiteramos, tanto el criterio de clasificación como la tarea de subsunción es técnica y jurídicamente necesaria, pero es menester que en la misma el operador jurídico se desenvuelva con una mirada realista y amplia de la situación fáctica que está sometida a su conocimiento, imponiendo un "camino de doble vía". Tal exigencia se materializa en esfuerzos y actividad exigible tanto para el ciudadano o profesional del derecho que encauza un reclamo y debe brindar material objetivo suficiente que funde la naturaleza del mismo, como para el órgano jurisdiccional que lo valore.

\section{Los derechos de incidencia colectiva: las asociaciones de consumidores y usuarios}

De las cuatro categorías precitadas, nos detendremos en este acápite en los mentados derechos de incidencia colectiva, en relación a los cuales intentaremos conceptualizarlos y describir su contenido para, luego, visualizar el modo en el cual las asociaciones de consumidores pueden actuar judicialmente en defensa de este tipo de derechos. Claramente, nada impide que un consumidor pueda titularizar derechos subjetivos, intereses legítimos o intereses simples, pero en lo tocante a la intervención de las asociaciones de consumidores cobran especial relevancia los derechos de incidencia colectiva, y por ello es que hemos tomado tal senda de estudio.

No obstante ello, también debemos reconocer que en relación a los mecanismos judiciales que se hallan instituidos en pos de tutelar dichas situaciones jurídicas prima, de mínima, una actualidad compleja en el derecho argentino atento la inexistencia de regulación legal y la consecuente construcción metodológica a partir del análisis de casos. A estos aspectos debemos sumar la crítica que se le endilga a los diversos proyectos legislativos que han pretendido la regulación de la materia (veáse Camps, 2018, pp. 15 y ss.). Lo particular de la situación encuentra su corolario en el hecho de que la propia Corte Suprema haya dictado dos acordadas (32/2014 y 12/2016) que regulan la materia. ${ }^{(9)}$

(9) La acordada 32/2014, al crear el Registro Público de Procesos Colectivos, radicados en los tribunales del Poder Judicial de la Nación, aclaró en su art. $1^{\circ}$ que involucraba a los procesos colectivos propiamente dichos, como a los referidos a intereses homogéneos múltiples. También delegó (art. $4^{\circ}$ ) en la Presidencia del Tribunal la facultad de dictar "todas las disposiciones complementarias y ejecutorias del reglamento que se aprueba". 


\subsection{Conceptualización y contenido de los derechos de incidencia colectiva}

Bustamante Alsina (1996, p. 896) alude a los intereses difusos como de carácter social y sostiene que tienen una incidencia colectiva supraindividual e indeterminada. A su turno, Flah y Smayensky (1993, p. 935) los definen como aquellos intereses que pertenecen idénticamente a una pluralidad de sujetos, en cuanto integrantes de grupos, clases sociales o categorías de personas ligadas en virtud de la pretensión de goce por parte de cada una de ellos de una misma prerrogativa. Stiglitz (1984, pp. 24-25) añade a la definición previa que la satisfacción de fragmento o porción de interés que atañe a cada individuo se extiende por naturaleza a todos; del mismo modo que la lesión a cada uno afecta simultánea y globalmente a los integrantes del conjunto comunitario.

Concordamos, asimismo, con Toricelli (2010, pp. 126-127) cuando señala la importancia de remarcar que la distinción entre derechos de pertenencia difusa y derechos colectivos en general es innecesaria, no solo por no ser clara conceptualmente, sino también por carecer de importancia práctica, dado que, a los efectos de procurar mecanismos de tutela, no existe diferencia que aconseje un tratamiento diverso, con lo cual se colige lo adecuado de su asimilación como una única categoría.

La conceptualización genérica de los intereses difusos, de los derechos de incidencia colectiva y sus caracteres propios y tipificantes resulta una ardua tarea cuyo agotamiento excede en gran medida la presente obra. ${ }^{(10)}$ Debe advertirse, sin embargo, que estos derechos se ubican dentro de una tercera etapa dentro del constitucionalismo, en la que se idearon los conocidos "derechos de tercera generación" en donde se le impone al Estado obligaciones de hacer con una presencia activa en la protección de los débiles. Esto ha tenido expresa recepción constitucional en la reforma de 1994 en la Argentina en una tendencia que no es privativa del derecho argentino, sino que le es común a la mayoría de los ordenamientos constitucionales occidentales. En suma, conforme enseña Vigo (2019, p. 1), surge clara la correlación entre los derechos de tercera generación, los derechos de incidencia colectiva y la vigencia del Estado de derecho constitucional.

Es nuestro deseo destacar la clasificación que la Corte Suprema de la Nación hizo en la precitada causa "Halabi", reafirmada en pronunciamientos posteriores, ${ }^{(11)}$ en donde distinguió dentro de los derechos de incidencia colectiva (como género) dos subtipos:

a) los derechos de incidencia colectiva que tienen por objeto bienes colectivos;

b) derechos de incidencia colectiva referentes a intereses individuales homogéneos.

(10) Una exposición ordenada y completa sobre las diferentes definiciones se puede encontrar en Cafferatta (2006, p. 1196 y ss.) a cuyo texto remitimos.

(11) Por ejemplo, en CSJN (Fallos 336:1236; 338:29). En el año 2016 hizo lo propio en "Centro de Estudios para la Promoción de la Igualdad y la Solidaridad (CEPIS) y otros..." (2016). 
Sobre los primeros, dijo el Tribunal que son aquellos que pertenecen a toda la comunidad, siendo indivisibles y no admitiendo exclusión alguna. Por ello es que no pueden ser objeto de apropiación individual, como sucede con el medio ambiente, cuyos titulares son siempre indeterminados, siendo su determinación solo una situación momentánea. Distinta es la situación en los derechos de incidencia colectiva referentes a intereses individuales homogéneos en los cuales no se patentiza un bien colectivo, dado que se afectan derechos individuales enteramente divisibles, hallándose un hecho único o continuado que provoca lesión de todos ellos y, por tanto, es identificable una causa fáctica homogénea.

En esta última categoría se destaca con asiduidad que encuadran los derechos -de raigambre constitucional- de los consumidores y los casos de discriminación. Ahora bien, aclaramos que si bien puede colegirse que los derechos de los consumidores y usuarios reconocen generalmente su naturaleza como intereses individuales homogéneos que ameritan una defensa jurisdiccional diferenciada -aunque pasible de agrupamiento para su articulación jurisdiccional-, debe memorarse que no necesariamente se identifica la totalidad de la naturaleza de los derechos de estos en dicha categoría. Es que si bien los derechos de consumidores y usuarios son el ejemplo primordial de los intereses individuales homogéneos, nada obsta que otras relaciones jurídicas tuteladas por el derecho puedan caber en relación a tales derechos $-v$. gr., derechos subjetivos o intereses legítimos-.

Entonces, la identificación de la naturaleza de la relación jurídica tutelada por el derecho adquiere notoriedad en materia de procesos colectivos que involucren a asociaciones de consumidores para, a partir de allí y como se verá en lo sucesivo, tener por existente o no su legitimación para accionar. Así, por caso, fue argüido judicialmente que en un amparo colectivo referente a intereses individuales homogéneos, la demanda no solo debe satisfacer los recaudos del amparo, que de por sí son rigurosos, sino también los presupuestos propios de ese tipo de acciones colectivas ${ }^{(12)}$ que seguidamente se tratarán, y, por ello, en orden a la legitimación de la asociación de consumidores, corresponde considerar si el derecho cuya protección procura la actora es de incidencia colectiva referente a intereses individuales homogéneos (CNac. Apel. Com., Sala C, 2019) o a la relación jurídica que pudiera corresponder.

En suma, nos parece acertada la distinción que hiciera la Corte en "Halabi" y creemos que goza de plena actualidad en nuestro derecho, fundamentalmente en base a lo que ha sido normado en el Código Civil y Comercial de la Nación (en adelante, $\mathrm{CCyC}$ ) relativo al ejercicio de derechos, resultando el precedente

(12) Así se sostiene en De los Santos Siatecki (2019, pp. 1399 y ss.), señalándose la referencia específica de los efectos comunes: identificación de un hecho único o complejo que cause la lesión, la constatación de que el ejercicio individual de las acciones no aparezca plenamente justificado y la garantía de una adecuada representación de todas las personas involucradas. 
de la Corte fuente directa del art. 14 de dicho cuerpo legal, el cual reconoce la existencia de dos tipos de derechos:

a) derechos individuales;

b) derechos de incidencia colectiva (ley 26.994, 2014).

Si bien el artículo no profundiza en la subclasificación de "Halabi", creemos que ella es totalmente operativa, debiendo incluirse dentro del inciso b) tanto a los derechos de incidencia colectiva que tienen por objeto bienes colectivos como a los derechos de incidencia colectiva referentes a intereses individuales homogéneos. ${ }^{(13)}$

De tal guisa, en lo que hace a la definición de la categoría de marras existe un entendimiento pacífico que fuera iniciado, primeramente, en la jurisprudencia del Máximo Tribunal argentino, para luego ser reafirmada y reconocida normativamente en el art. 14 del Código Civil y Comercial de la Nación (ley 26.994, 2014) en un todo concordante con la tradición jurisprudencial bordada en derredor del caso "Halabi".

\subsection{Las asociaciones de consumidores y usuarios}

En orden a la legitimación colectiva de las asociaciones de consumidores, pese a que el propio fallo "Halabi" en su considerado 21 se sustentó en el art. 54 de la ley 24.240, fue necesario que la Corte dictara el precedente "Padec" (2013) y luego de este se sucedieran otros 55 fallos $^{(14)}$ más para que se consolidara la admisión de su legitimación. Relata Tambussi (2018) que a través de los precedentes de la Corte Suprema de Justicia de la Nación se estableció que, de conformidad con lo dispuesto por el art. 43 de la Constitución Nacional, las asociaciones de usuarios y consumidores están legitimadas para iniciar acciones colectivas que tengan por objeto la tutela de intereses individuales homogéneos, incluso de naturaleza patrimonial, siempre que se cumplimenten determinados recaudos; a saber:

1) la existencia de un hecho único susceptible de ocasionar una lesión a una pluralidad de sujetos;

2) que la pretensión esté concentrada en los efectos comunes para toda la clase involucrada, y;

3) que el no reconocimiento de la legitimación procesal pueda comprometer el acceso a la justicia de los integrantes del colectivo (p. 79 y ss.).

Brun y Jaime (2015, p. 219) destacan que el intérprete debe inexcusablemente repasar los tres elementos o presupuestos que deben verificarse para lo procedencia de una acción colectiva en resguardo de intereses individuales

(13) En un mismo sentido: Lorenzetti (2014, pp. 72-76), Tolosa (2016, p. 39) y Pagés Lloveras (2015, p. 79 y ss.).

(14) El número le corresponde a Berstein (2016, p. 35).

70 | Ediciones SAIJ < Ministerio de Justicia y Derechos Humanos de la Nación 
homogéneos (a saber: causa fáctica común, pretensión enfocada en el aspecto colectivo y constatación de que el ejercicio individual no aparece justificado), como así también el cumplimiento de las pautas adjetivas establecidas -ante la ausencia de un marco normativo referido a procesos colectivos- para determinar la admisión formal de la acción colectiva (entre otras, precisa identificación del grupo o colectivo afectado, idoneidad del representante, planteo que involucre -por sobre los aspectos individuales- cuestiones de hecho y derecho comunes y homogéneas a todo el colectivo).

La judicatura ha explicitado cada uno de dichos requisitos:

a) la verificación de una causa fáctica común -hecho único o complejo que causa una lesión a una pluralidad relevante de derechos individuales-;

b) una pretensión procesal enfocada en el aspecto colectivo de los efectos de ese hecho -la causa no debe relacionarse con el daño diferenciado(15) que cada sujeto pudiera sufrir en su esfera, sino con los elementos homogéneos que tiene esa pluralidad de sujetos al estar afectados por un mismo hecho-;(16)

c) la constatación de que el ejercicio individual no aparece plenamente justificado -el interés individualmente considerado no justifica la promoción de una demanda, con lo que podría verse afectado el acceso a la justicia(CNac. Civ. y Com. Fed., Sala III Mar del Plata, 2020).

A estos presupuestos o requisitos, que hacen más a la materia del fondo de la cuestión debatida aunque deban ser analizados en el prolegómeno de una demanda judicial, deben sumársele, en el ámbito de la justicia de la Nación -fueros federal y nacional-, una variedad de exigencias formales dispuestas por la Corte Nacional a través del dictado de las acordadas 32/2014 y 12/2016, con el fin de prevenir que se menoscabe la garantía del debido proceso legal. Particularmente se atendió a la necesidad de que se adopten pautas mínimas indispensables de prelación para evitar pronunciamientos contradictorios derivados de procesos colectivos en los que se ventilan pretensiones sobre un mismo bien jurídico (conf. considerando $7^{\circ}$ de la acordada $12 / 2016$ y sus citas) (CNac. Civ. y Com. Fed., Sala II, 2017, p. 46), invitando a los superiores tribunales de las provincias y CABA a celebrar convenios con el Máximo Tribunal en tal sentido (punto 3 del acuerdo 32/2014).

(15) En un caso, una asociación de consumidores perseguía la reclamación del daño moral sufrido por titulares de cajas de seguridad cuyos cofres no habían sido violentados en un hecho delictivo, fallándose que, como los consumidores representados no sufrieron daño patrimonial alguno, la eventual afectación de cada uno de ellos descarta la existencia de intereses individuales homogéneos que justifiquen la promoción de la acción (CNac. Apel. Com., Sala F, 2017).

(16) Ello no quita que dentro del grupo que conforma el polo activo de la pretensión colectiva pueda observarse la presencia de subcategorías, y que aquello pudiera proyectar distinciones a la hora de resolver sobre ciertas cuestiones particulares, mas no significa, de ningún modo, la ausencia de configuración de la causa fáctica y jurídica en común, extremo trascendental a la hora de tener por conformada la clase (CNac. Civ. y Com. Fed., Sala II, 2020). 
Estimamos que la facilitación del acceso a la jurisdicción tiende a concretar una multiplicidad de principios, entre ellos, la igualdad, debiéndose procurar, en consecuencia, una tutela al consumidor que garantice un acceso irrestricto a la justicia y no condicionado a factores económicos (Bellusci de Zavala González y Solá, 2011, p. 85). Esto último dado que la eficacia de las medidas protectivas del consumidor no solo dependen del reconocimiento de derechos, sino en igual medida y especialmente de los medios adecuados y eficaces para ejercerlos (Stiglitz, 1994, p. 317). Pero cuidado, no se trata para nosotros de una admisión "amplísima" de la legitimación procesal aquí tratada sino que la misma se habilitará cuando la pretensión esté concentrada en los efectos comunes -derivada de la homogeneidad de los intereses involucrados (CSJN, Fallos 340:1973)- y no en lo que cada individuo puede peticionar (CSJN, Fallos 335:1080).

En el año 2016 se planteó ante la Corte Nacional un caso de ribetes particulares en relación a la defensa de los derechos de consumidores y usuarios como fue el caso "Abarca" (2016) que toca variados aspectos relativos al tópico aquí tratado. La Corte, con acierto, planteó que los partidos políticos exorbitarían sus papeles si se los autorizara para operar como las "asociaciones" del art. 43 de la Constitución, ya que es esta misma la que asigna a dichas entidades, y no a los partidos, legitimación para la tutela de los intereses de incidencia colectiva. El fallo reitera que los partidos no deben distraerse de sus objetivos específicos, consistentes en profundizar los derechos políticos de los ciudadanos y la calidad institucional dentro de una sociedad democrática (Sagüés, 2016, p. 1198).

En suma, no puede divorciarse el análisis sobre la legitimación procesal de las asociaciones de consumidores de la naturaleza de la relación jurídica protegida cuya afectación o amenaza sirve de base y antecedente de la pretensión toda vez que no es conducente habilitar instancia judicial alguna en tutela de derechos cuyo ejercicio aquellas, por la propia entidad y naturaleza de los mismos, no pueden abrogarse. Para ello se impone, primero, un conocimiento acabado de las categorías jurídicas en juego para luego, en base a las mismas, poder subsumir el caso concreto en alguna de las mismas, lo que de rondón definirá asertiva o negativamente la posibilidad de que la acción judicial de marras pueda ser intentada por una asociación de consumidores o si, por el contrario, y en palabras de la Corte Nacional, se cuenta con incentivos suficientes para accionar de manera individual sin que resulte necesario que una asociación asuma la representación de su interés (CSJN, 2014).

\section{El capítulo XIV de la ley $\mathbf{2 4 . 2 4 0}$}

Metodológicamente, hemos optado por asignarle un acápite propio al tratamiento del capítulo XIV de la ley 24.240 (Ley de Defensa del Consumidor) por dos motivos: primero por la especialidad de su regulación y, segundo, por las particularidades y entresijos que el mismo reconoce para sí, lo cual nos hará inquirir sobre su real utilidad en la temática. Asimismo, aclaramos que el estudio de la 
cuestión se halla en relación a la temática de este opúsculo, vale decir, no agotaremos todos y cada uno de los extremos de la regulación legal sino en la medida en que hagan a la utilidad de discernir en un proceso judicial la adecuada legitimación activa que pueda reconocer una asociación de consumidores.

El capítulo en cuestión consiste en cuatro artículos -55 al 58-, de los cuales el 55, en concordancia con lo dispuesto en el art. 52,(17) se ocupa de la legitimación:

Las asociaciones de consumidores y usuarios constituidas como personas jurídicas reconocidas por la autoridad de aplicación, están legitimadas para accionar cuando resulten objetivamente afectados o amenazados intereses de los consumidores o usuarios, sin perjuicio de la intervención de éstos prevista en el segundo párrafo del artículo 58 de esta ley...". (ley 24.240, 1993, según texto de la reforma ley $26.361,2008)^{(18)}$

Pues bien, de la simple lectura de la disposición salta a la vista la utilización de denominaciones diversas a las que venimos utilizando en este trabajo puesto que se refiere a afectaciones objetivas o amenazas a intereses de los consumidores o usuarios, con lo cual, a los efectos de evitar desavenencias interpretativas, invitamos a que el art. 55 se lea en clave de las categorías de relaciones jurídicas tuteladas por el derecho que ut supra se estudiaran.

En cuanto a la formación como personas jurídicas -asociaciones civiles-, va de suyo que es forzosa la constitución de las asociaciones de conformidad con los arts. 141 y 168-186 y concordantes del Código Civil y Comercial de la Nación en lo que a su personalidad jurídica respecta. A ello se le añaden los arts. 56 y 57 de la Ley de Defensa del Consumidor (ley 24.240, 1993) los cuales contienen una extensa enunciación sobre, primero, los fines que la asociación debe perseguir para poder solicitar autorización a la autoridad de aplicación para funcionar (art. 56) y, segundo, otros requisitos que la normativa consumeril, denominados "condiciones especiales"(19) establece para obtener el reconocimiento estatal como tales (art. 57).

(17) El mismo reza: "Sin perjuicio de lo dispuesto en esta ley, el consumidor y usuario podrán iniciar acciones judiciales cuando sus intereses resulten afectados o amenazados. La acción corresponderá al consumidor o usuario por su propio derecho, a las asociaciones de consumidores o usuarios autorizadas en los términos del artículo 56 de esta ley, a la autoridad de aplicación nacional o local, al Defensor del Pueblo y al Ministerio Público Fiscal (...) En las causas judiciales que tramiten en defensa de intereses de incidencia colectiva, las asociaciones de consumidores y usuarios que lo requieran estarán habilitadas como litisconsortes de cualquiera de los demás legitimados por el presente artículo, previa evaluación del juez competente sobre la legitimación de estas" (ley 24.240, 1993, según texto de la reforma operada a través de la ley 26.361, 2008).

(18) Según texto publicado en http://servicios.infoleg.gob.ar/infoleglnternet/verNorma.do?id=638, consultado el 01/03/2021.

(19) "Requisitos para Obtener el Reconocimiento. Para ser reconocidas como organizaciones de consumidores, las asociaciones civiles deberán acreditar, además de los requisitos generales, las siguientes condiciones especiales: a) No podrán participar en actividades políticas partidarias; b) Deberán ser independientes de toda forma de actividad profesional, comercial y productiva; c) No podrán recibir donaciones, aportes o contribuciones de empresas comerciales, industriales o proveedoras de servicios, privadas o estatales, nacionales o extranjeras; d) Sus publicaciones no podrán contener avisos publicitarios", según texto publicado en http://servicios.infoleg. gob.ar/infoleglnternet/verNorma.do?id=638, consultado el 01/03/2021. 
Dicho estudio es materia de análisis, originalmente, de la autoridad de aplicación pero, en lo sucesivo, dicha inscripción registral debe mantenerse durante toda la tramitación del pleito, aspecto que ha merecido expresa aclaración de la Corte Nacional en el año 2016 al entender que, en oportunidad de resolver un conflicto negativo de competencia, el mismo era inoficioso en tanto se verificaba la baja de la asociación actora del registro correspondiente pues la inscripción en el referido registro es un presupuesto necesario para que las asociaciones puedan accionar en el ámbito nacional, en representación de los intereses de usuarios y consumidores ( CSJN, "Asociación Sepa Defenderse...", 2016, p. 127). Entonces, queda definido tanto en el texto de la norma (arts. 55, 56, 57) como en la interpretación del Máximo Tribunal que la inscripción y vigencia registral es un presupuesto necesario e ineludible de la legitimación procesal de las asociaciones de consumidores.

A su turno, el último artículo del capítulo XIV -el art. 58- de la Ley de Defensa del Consumidor no será tratado detalladamente en este trabajo dado que su ámbito de aplicación escapa a los márgenes de este opúsculo, los cuales vienen dados por la intervención judicial en la faz activa de una asociación de consumidores, mientras que el art. 58 establece un mecanismo de actuación extrajudicial de negociación o acercamiento entre consumidores y proveedores reglando que los reclamos de aquellos por el incumplimiento de la norma podrá sustanciarse a través de la asociación de consumidores, la cual, una vez suscripta la petición ante la asociación correspondiente, adjuntando la documentación e información que obre en poder del consumidor, procurará acercar a las partes convocándolas a las reuniones que considere oportunas, con el objetivo de intentar una solución al conflicto planteado a través de un acuerdo satisfactorio. Expresamente aclara la norma: "En esta instancia, la función de las asociaciones de consumidores es estrictamente conciliatoria y extrajudicial, su función se limita a facilitar el acercamiento entre las partes" (ley 24.240, 1993).

\section{Valoraciones conclusivas}

De lo vertido hasta aquí podemos extraer algunas consideraciones finales. Por un lado, es ponderable que el intérprete entienda que las clásicas categorías de clasificación en torno a la relación jurídica protegida $-v$. gr. derecho subjetivo, interés legítimo, interés simple y derechos de incidencia colectiva- no pueden asimilarse a una noción estática, puesto que, si bien las categorías gozan de actualidad, su contenido y utilidad se halla en constante reformulación para dar una acabada respuesta a la pluralidad de situaciones y demandas que exigen el régimen de tutela al consumidor.

Dado que en la práctica la distinción entre las diversas situaciones jurídicas tuteladas y su correlato con la legitimación activa ha servido muchas veces solo para restringir las vías posibles a los ciudadanos, ${ }^{(20)}$ proponemos, tal como

(20) A esta conclusión arriba Zannoni (2005, p. 59) en lo tocante a la relación entre vía recursiva y relación jurídica protegida en lo tocante a la reclamación de daños y perjuicios, en una conclusión, estimamos, plenamente aplicable al caso de marras. En materia de daños recorda- 
lo venimos haciendo en líneas anteriores, una readecuación de dichas categorías a las exigencias normativas plasmadas en el Código Civil y Comercial de la Nación, las cuales se manifiestan como plenamente concordantes con los desarrollos de autorizada doctrina y guiados por el necesario norte del acceso a la jurisdicción como expresas exigencias constitucionales y convencionales reconocidas en una retahíla de fallos nacionales e internacionales.

Ciertamente, la aplicación práctica del derecho ha dado muestras sobradas de la necesidad de moderar rigideces legales, esbozando nuevos principios procesales como el favor processum, el más renombrado in dubio pro actione, o incluso la subsunción oficiosa de un acto procesal y la posibilidad de retipificarlo a la hora de resolver (recalificación y reconducción de postulaciones) en base al iura novit curia como distintas manifestaciones de una reformulación de los tradicionales preceptos procesales y de acceso a la justicia.

Todo lo dicho pone de manifiesto la notable impronta constitucional de los procesos de recodificación que demarcan nuestros días, siendo aquellos ricos en reglas indeterminadas, directrices, principios y valores, con la finalidad de permitir una mayor vinculación con la Constitución, diferenciándose así notoriamente de los procesos de codificación decimonónicos. De tal guisa, se logra asimilar este proceso de recodificación con el avance constitucional que procura orientar de modo creciente al resto de la juridicidad, penetrando directamente en espacios donde antes debía mediar la legislación. El proceso de codificación era más legal; la recodificación argentina está constitucionalizada y acrecienta el papel de los jueces en la producción de derecho privado (Chaumet y Meroi, 2016, p. 35 y ss.).

En este tren, concebimos que las asociaciones de consumidores son un actor preponderante en la tutela de una de las categorías en particular como es la de los derechos de incidencia colectiva, tanto que estos recaigan sobre bienes colectivos o trasunte un interés individual homogéneo. La judicatura ha compartido este entendimiento y bregamos por su mantenimiento dado que la unificación de reclamos en una representación común permite superar la anquilosada noción de que cada afectado debe, individualmente, iniciar su reclamo particular en su propio beneficio. Por el contrario, la acción de las asociaciones de consumidores permite un alcance mayor de la sentencia judicial que pudiere caber y, por ende, propende una efectividad mayor de la tutela de los derechos de los consumidores.

mos que el art. 1737 del Código Civil y Comercial argentino reza: "Hay daño cuando se lesiona un derecho o un interés no reprobado por el ordenamiento jurídico, que tenga por objeto la persona, el patrimonio, o un derecho de incidencia colectiva". Habiéndose optado por una conceptualización amplia del daño, creemos que la lectura a hacerse sobre el derecho o interés afectado debe ser de idéntica manera sin perjuicio del deber del actor de acreditar inexcusablemente los restantes requisitos del daño. Modernamente, se tiende a la amplitud de lo que por daño debe entenderse, así como también a ampliar el catálogo de responsables (Lorenzetti, 1991, p. 586 y ss.). 
Si bien nada impide su reclamo particular, la existencia de estas asociaciones y su desenvolvimiento en procesos judiciales de consumo se presenta como un aspecto encomiable sobre el cual nos hemos permitido precisar algunos conceptos en orden a auxiliar al operador jurídico -juez, profesional del derecho o, incluso, el propio consumidor- que deba dilucidar un supuesto particular en el cual se verifique la interacción de una asociación de consumidores. Con el deseo de que estas líneas ayuden, en la medida de lo posible, a ampliar la posibilidad de tutela jurisdiccional de los derechos de los consumidores, vaya, pues, nuestro aporte.

\section{Referencias bibliográficas}

Alvarado Velloso, A. (2005). Introducción al estudio del derecho procesal. Segunda parte. Rubinzal Culzoni Editores.

Arazi, R. (2004). Derecho Procesal Civil y Comercial. Tomo 1 (2ª ed.). Rubinzal Culzoni Editores.

Barra, R. C. (1980). Principios de derecho administrativo. Ábaco.

Bellusci de González Zavala, F. y Solá, V. (2011). Los principios en el proceso de consumo. Revista Derecho Civil Comercial y de la Empresa, (octubre).

Berstein, H. L. (2016). ¿Concluye la polémica sobre el alcance del beneficio de justicia gratuita? Revista Jurisprudencia Argentina.

Brun, C. A. y Jaime, F. (2015). Las "acciones de clase" y la determinación del colectivo representado en juicio. Revista Responsabilidad Civil y Seguros 2015-VI, 219.

Bustamante Alsina, J. (1996). El daño ambiental y las vías procesales de acuerdo a la jurisprudencia. Revista Jurisprudencia Argentina, 1996-IV.

Cafferatta, N. A. (2006). Los derechos de incidencia colectiva. La Ley, 2006-A.

Camps, C. E. (2018). El anteproyecto de ley de procesos colectivos de Justicia 2020 frente a la eficacia. Revista de Derecho Ambiental, 57, 15.

Carnelutti, F. (1959). Instituciones del Proceso Civil. Tomo I. S. Sentís Melendo, S. (Trad.). EJEA.

Chaumet, M. E. y Meroi, A. A. (2016). Constitucionalización del derecho y recodificación del derecho privado. Revista Jurisprudencia Argentina, p. 35 y ss.

De los Santos Siatecki, N. M. (2019). La legitimación activa en las acciones colectivas referidas a intereses individuales homogéneos y a quiénes comprende. Revista de Derecho Administrativo, 2019-126.

Fiorini, B. A. (1997). ¿Qué es el contencioso? AbeledoPerrot.

Flah, L. y Smayensky, M. (1993). La regulación procesal en el derecho ambiental americano. La Ley, 1993-E.

García Pullés, F. R. (2004). Tratado de lo contencioso administrativo. Tomo II. Hammurabi.

Gordillo, A. (2003). Tratado de Derecho Administrativo. Tomo // (6ª ed.), Fundación de Derecho Administrativo.

76 | Ediciones SAIJ < Ministerio de Justicia y Derechos Humanos de la Nación 
Gozaíni, O. A. (1999). Teoría general del derecho procesal. Jurisdicción, acción y proceso. Ediar.

Gozaíni, O. A. (2012). La legitimación procesal para obrar en la defensa de los llamados intereses difusos. Revista de Derecho Civil Comercial y de la Empresa, (agosto), 119.

Guasp, J. (1996). Estudios Jurídicos. La pretensión procesal. Civitas.

Lorenzetti, R. L. (1991). La legitimación pasiva y el litisconsorcio en el proceso de daños. La Ley, 1991-E, 586.

Lorenzetti, R. L. (2014). Comentario al Título Preliminar. En R. L. Lorenzetti (Dir.) M. F. De Lorenzo y P. Lorenzetti (Coords.) Código Civil y Comercial de la Nación comentado. Tomo I. Rubinzal-Culzoni Editores.

Marienhoff, M. F. (1986). La legitimación en las acciones contra el Estado (Acción popular, interés simple, interés difuso, acto administrativo discrecional). La Ley, 1986-C.

Morello, A. M. y Stiglitz, G. A. (1986). Tutela procesal de los derechos personalísimos e intereses colectivos. Librería Editora Platense.

Pagés Lloveras, R. M. (2015). Acciones colectivas, de clase y derechos individuales homogéneos. Revista Responsabilidad Civil y Seguros, 2015-IX.

Palacio, L. E. (1970). Derecho Procesal Civil. Tomo III.. AbeledoPerrot.

Sagüés, N. P. (2016). Los partidos políticos como asociaciones amparistas de usuarios y consumidores. La Ley, 2016-F.

Stiglitz, G. A. (1984). La responsabilidad civil: nuevas formas y perspectivas. La Ley.

(1994). Defensa de los consumidores de productos y servicios. La Rocca.

(2015). Los principios del Derecho del Consumidor y los Derechos Fundamentales. En G. A. Stiglitz y C. A. Hernández (Dirs.) Tratado de Derecho del Consumidor. Tomo I. La Ley.

Tambussi, C. E. (2018). Las asociaciones de consumidores ante incumplimientos masivos de deberes del proveedor. Revista Responsabilidad Civil y Seguros, 2018-IV.

Tolosa, P. (2016). La noción de derechos de incidencia colectiva en el nuevo código civil y comercial, Revista Responsabilidad Civil y Seguros, 2016-II.

Toricelli, M. (2010). Organización constitucional del poder. Tomo I. Astrea.

Trionfetti, V. (2010). El sistema de control de constitucionalidad en Argentina. En E. M. Falcón (Dir.) Tratado de Derecho Procesal Constitucional. Tomo I. Rubinzal Culzoni Editores.

Vigo, R. L. (2019a). ¿Estado de derecho legal o Estado legal de derecho? Diario La Ley.

(2019b) ¿Estado de derecho constitucional o estado constitucional de derecho? Diario La Ley.

Zannoni, E. A. (2005). El daño en la responsabilidad civil (3a ed.). Astrea. 


\section{Referencias jurisprudenciales}

CSJN, "Botta, Rodolfo Mauricio c/ Junta Electoral de la Unión Cívica Radical”, 24/03/1987, Fallos: 310:670.

------, "Ruiz, Mirtha Edith y otro c/ Provincia de Buenos Aires s/ daños y perjuicios", 07/11/1989, Fallos 312:2138

------, "Porcelli, Luis A. c/ Banco de la Nación Argentina s/ cobro de pesos", 20/04/1989, Fallos 312:555.

-------, "Polino, Héctor y otro c/ Poder Ejecutivo (Exp. Feria 5/94) s/ amparo", 07/04/1994, Fallos 317:335.

------, "Asociación Trabajadores del Estado c/ Estado Nacional - Poder Ejecutivo Nacional Jefatura de Gabinete de Ministros s/ acción de amparo", 10/12/1997, Fallos 320:2603.

-------, "Rodríguez, Jorge - Jefe de Gabinete de Ministros de la Nación s/ plantea cuestión de competencia", 17/12/1997, Fallos 320:2851.

-------, "Mujeres por La Vida - Asociación Civil sin Fines de Lucro- filial Córdoba c/ Estado Nacional - PEN - Ministerio de Salud y acción social de la Nación s/ amparo", 31/10/2006, Fallos 329:4593.

------, "Halabi, Ernesto c/ P.E.N. -ley 25.873 - dto. 1563/04 s/ amparo”, 24/02/2009, Fallos $332: 111$

------, "Cavalieri Jorge y otro c/ Swiss Medical S.A. s/ amparo", 26/06/2012, Fallos 335:1080.

-------, "Padec c/ Swiss Medical SA s/ nulidad de cláusulas contractuales", 21/08/2013, Fallos 336:1236

-------, "Consumidores Financieros Asociación Civil p/defensa c/ Prudencia Cía. Argentina de Seguros Generales S.A. s/ ordinario", 27/11/2014, CSJ 161/2013 (49-C), C. 161. XLIX. REX.

------, "Asociación Civil para la Defensa en el Ámbito Federal e Internacional de Derechos c/ Instituto Nacional de Servicios Sociales para Jubilados y Pensionados s/ amparo", 10/02/2015, Fallos 338:29.

-------, "Abarca, Walter José y otros c/ Estado Nacional - Ministerio Energía y Minería y otro s/ amparo ley 16.986", 06/09/2016, Fallos 339:1223.

-------, "Asociación Sepa Defenderse c/ Secretaría de Energía de la Nación y otros s/ amparo colectivo", 26/12/2016.

-------, "Centro de Estudios para la Promoción de la Igualdad y la Solidaridad (CEPIS) y otros c/ Ministerio de Agricultura y Minería s/ amparo colectivo", 18/08/2016, Fallos 339:1077.

," "Consumidores Financieros Asociación Civil p/ su defensa c/ La Nueva Cooperativa de Seguros Limitada s/ ordinario”, 26/12/2017, Fallos 340:1973.

78 | Ediciones SAIJ < Ministerio de Justicia y Derechos Humanos de la Nación 


\section{Cámaras de Apelaciones}

CNac. Apel. Com., Sala F, "Consumidores Financieros Asociación Civil para su Defensa c/ Banco de la Provincia de Buenos Aires SA s/ ordinario", 08/06/2017.

CNac. Apel. Com., Sala C, "Asociación por la Defensa de Usuarios y Consumidores c/ FCA Automobiles Argentina S.A. s/ Sumarísimo", 18/06/2019.

CNac. Civ. y Com. Fed., Sala II, "Usuarios y Consumidores Unidos c/ Obra Social de la Unión del Personal Civil de la Nación s/ incumplimiento de prestación de obra social/med. prepaga", 29/10/2020.

CNac. Civ. y Com. Fed., Sala II, "Asociación por la Defensa de Usuarios y Consumidores c/ EDESUR SA s/ daños y perjuicios", 06/10/2017.

CNac. Civ. y Com. Fed., Sala III Mar del Plata, "Protegiendo al Consumidor c/ Simone Automotores S.A. s/ repetición de sumas de dinero", 24/07/2020.

\section{Juzgados de primera instancia}

JFed. 1ำ Instancia Dolores, "Consumidores Argentinos Asociac. para la Defensa, Educación e Información de los Consumidores C/ P.E.N. y Otros s/ acción declarativa de inconstitucionalidad", 21/05/2018. 